\title{
Mesoporous Structure Control of Silica in Room-Temperature Synthesis under Basic Conditions
}

\author{
Jeong Wook Seo, ${ }^{1}$ Woo-Jin Lee, ${ }^{2}$ Seongju Nam, ${ }^{3}$ Heekyoung Ryoo, ${ }^{3}$ \\ Jong-Nam Kim, ${ }^{1}$ and Chang Hyun $\mathrm{Ko}^{3}$ \\ ${ }^{1}$ Petroleum-Gas Research Center, Korea Institute of Energy Research, Daejeon 305-343, Republic of Korea \\ ${ }^{2}$ Corrosion Research Center, Department of Chemical Engineering and Materials Science, University of Minnesota, \\ Minneapolis, MN 55455, USA \\ ${ }^{3}$ School of Applied Chemical Engineering, Chonnam National University, Gwangju 500-757, Republic of Korea
}

Correspondence should be addressed to Jong-Nam Kim; jnkim@kier.re.kr and Chang Hyun Ko; chko@jnu.ac.kr

Received 8 October 2014; Revised 31 December 2014; Accepted 31 December 2014

Academic Editor: Abdelwahab Omri

Copyright (C) 2015 Jeong Wook Seo et al. This is an open access article distributed under the Creative Commons Attribution License, which permits unrestricted use, distribution, and reproduction in any medium, provided the original work is properly cited.

\begin{abstract}
Various types of mesoporous silica, such as continuous cubic-phase MCM-48, hexagonal-phase MCM-41, and layer-phase spherical silica particles, have been synthesized at room temperature using cetyltrimethylammonium bromide as a surfactant, ethanol as a cosurfactant, tetraethyl orthosilicate as a silica precursor, and ammonia as a condensation agent. Special care must be taken both in the filtering of the resultant solid products and in the drying process. In the drying process, further condensation of the silica after filtering was induced. As the surfactant and cosurfactant concentrations in the reaction mixture increased and the $\mathrm{NH}_{3}$ concentration decreased, under given conditions, continuous cubic MCM-48 and layered silica became the dominant phases. A cooperative synthesis mechanism, in which both the surfactant and silica were involved in the formation of mesoporous structures, provided a good explanation of the experimental results.
\end{abstract}

\section{Introduction}

Design and control of morphology and pore structure of nanostructured materials and catalyst support are of great importance for the green chemistry and renewable energy production because bulk materials and conventional catalyst support are not suitable for these aims. In 1992, scientists working for Mobil reported pioneering work on the synthesis of a series of ordered mesoporous silicas, M41S [1-3]. They explained the synthesis of the mesoporous silica using a liquid crystal template mechanism: an organic surfactant formed liquid crystal micelles, and inorganic precursors were subsequently polymerized on the template. These reports stimulated many researchers to study mesoporous materials because mesoporous silica was found to have many advantages, such as large pore size $(3-10 \mathrm{~nm})$, high surface area, and narrow pore size distribution. After further studies, an improved model was proposed, namely, a cooperative mechanism, in which inorganic precursors and organic surfactants were cooperatively involved in the formation of mesoporous silica $[4,5]$. On the basis of this improved understanding, researchers have tried to control mesoporous structures by changing the molecular structures of the surfactants or by using additives. Continuous cubic (Ia3d) MCM-48 was synthesized by adding ethanol as a cosurfactant or by changing the type of surfactant from a mono-alkyl-chain quaternary amine salt to a gemini surfactant, based on the conditions for hexagonal $(p 6 \mathrm{~mm}) \mathrm{MCM}-41$ synthesis [6, 7]. As these types of conventional hydrothermal synthesis typically take place at higher temperatures, that is, close to $373 \mathrm{~K}$, thermally stable products can be obtained. Postsynthesis treatments, such as filtering, washing, and drying at $373 \mathrm{~K}$, therefore, do not affect the structure of the mesoporous silica.

Various types of mesoporous silica thin films and spherical particles have recently been synthesized at room temperature by an evaporation-induced self-assembly (EISA) method and by a modified version of the Stöber method. In the EISA method, mesoporous silicas were synthesized under acidic 
conditions using cetyltriethylammonium bromide (CTEABr) or cetyltrimethylammonium bromide (CTABr) as the surfactant [8-13]. The modified Stöber method was adopted for the synthesis of mesoporous silicas with various pore structures, such as MCM-41 and MCM-48, under basic conditions [14-16]. Each of the studies focused on the synthesis of either MCM-41 type or MCM-48 type mesoporous silica. For example, Schumacher et al. synthesized MCM-48 and Grün et al. controlled the porosity and morphology of MCM$41[14,15]$. There has been little research on the control of pore structures by adjusting the preparation procedure. There is therefore considerable scope for investigation of mesoporous silica synthesis, particularly, in terms of porestructure control.

In this study, various types of mesoporous silica were synthesized under a wide range of experimental conditions, based on the modified Stöber method. Unlike hydrothermal synthesis at high temperature, special care must be taken after filtration of the resultant reaction product to set up a reliable experimental procedure. Based on this procedure, experimental factors, including the molar ratios of ethanol, water, and ammonia, were investigated and correlated with the product mesostructures. A good interpretation of the experimental results was given by a cooperative synthesis mechanism.

\section{Experimental Section}

2.1. Mesoporous Material Synthesis. This synthesis method was a modification of the Stöber method used for the preparation of nonporous silica spheres [17]. The mesoporous silica samples were prepared using tetraethyl orthosilicate (TEOS, Aldrich) as the silica source, cetyltrimethylammonium bromide (CTABr, Aldrich) as the surfactant, ethanol (EtOH, Junsei) as the cosurfactant, ammonia solution $\left(\mathrm{NH}_{3}\right.$, $28 \mathrm{wt} \%$, Junsei) as the agent for silicate condensation, and deionized water as the solvent.

In a typical synthesis, CTABr $(0.9 \mathrm{~g})$ was dissolved in deionized water (57.5 g). EtOH (23.4 g) and TEOS (2.7 g) were added to the solution. Finally, $28 \mathrm{wt} \%$ ammonia solution (15.4 g) was added dropwise to the reaction mixture, over a period of $30 \mathrm{~min}$, with vigorous stirring. The typical molar composition of the reaction mixture was TEOS : CTABr: EtOH : $\mathrm{NH}_{3}: \mathrm{H}_{2} \mathrm{O}=1.0: 0.2: 40: 20: 300$. When the addition of the ammonia solution was completed, the reaction mixture was stirred for an additional $2 \mathrm{~h}$, prior to aging under static conditions for $2 \mathrm{~h}$. After the aging step, the reaction mixture was filtered and a solid product was obtained, with or without washing. The solid product was then dried in an oven for $72 \mathrm{~h}$ at $298 \mathrm{~K}$. The molar composition of the reactant mixture was as follows:

$$
\begin{aligned}
& \text { 1.0TEOS : } m \text { CTABr }: x \text { EtOH }: y \mathrm{NH}_{3}: z \mathrm{H}_{2} \mathrm{O} \\
& (m=0.2-0.5, x=20-70, y=20-70, z=200-700) .
\end{aligned}
$$

The as-synthesized mesoporous silica samples were calcined at $823 \mathrm{~K}$ for $4 \mathrm{~h}$ in an oxygen environment to provide the final products.

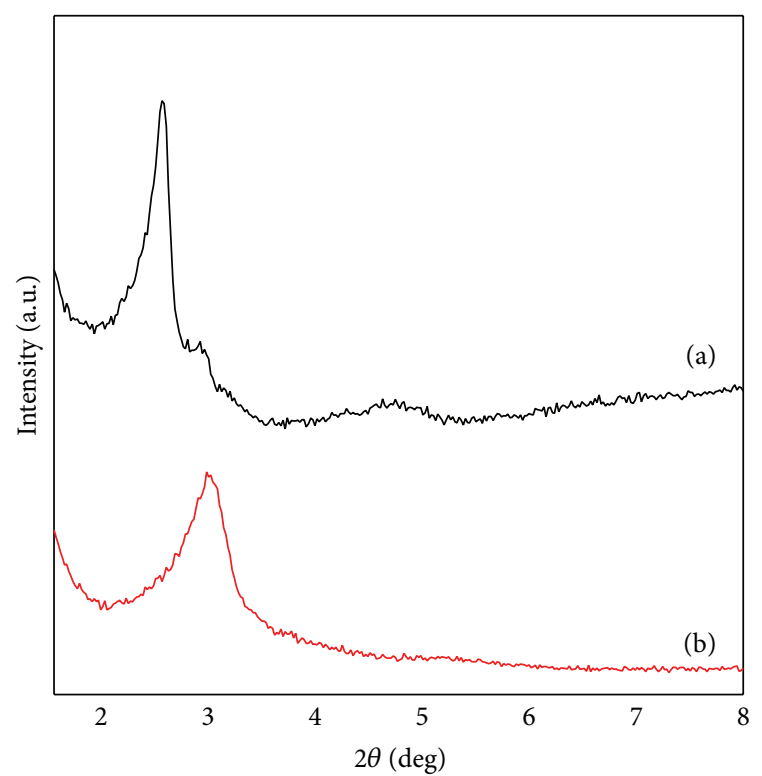

FIGURE 1: Effects of washing on the structure of mesoporous silica: (a) without washing and (b) washing with water during or after filtration of the reaction product.

2.2. Mesoporous Material Synthesis. X-ray powder diffraction (XRD) patterns were obtained using Rigaku D/Max 2000 diffractometer with $\mathrm{Cu} \mathrm{K}_{\alpha}$ radiation $(\lambda=0.15418 \mathrm{~nm}, 30 \mathrm{kV}$, and $20 \mathrm{~mA}$ ) in the range $1.2^{\circ}$ to $10^{\circ}$ with a $0.01^{\circ}$ step-size.

\section{Results and Discussion}

3.1. Sample Treatment Conditions for Ordered Mesoporous Silica. Figure 1 shows the effects of water washing after filtration of the reaction mixture in mesoporous silica formation. The two samples shown in Figure 1 have identical reactant compositions. They underwent identical synthesis procedures, apart from washing. When the washing procedure was not applied to the resultant silica product after filtration, wellordered MCM-48 phase (Ia3d) was obtained, as shown in Figure 1(a). However, washing converted the well-ordered mesoporous silica into poorly ordered one, as shown in Figure 1(b). Unlike the product obtained by hydrothermal synthesis, in which condensation of the silicate precursors is accomplished during thermal treatment, the silica-surfactant mesostructure obtained by room-temperature synthesis was fragile enough to be destroyed by simple water washing, as a result of the absence of heat treatment. This indicates that the silicate condensation reaction did not reach the completion stage, despite the use of ammonia as a silicate condensation agent. This strongly suggests that additional reaction time is necessary during room-temperature synthesis for further silicate condensation.

In order to identify factors which would enhance the condensation conditions for the filtered mesoporous silica, the drying conditions were initially investigated. Figure 2(a) demonstrates that drying at room temperature for $3 \mathrm{~d}$ in an oven produced well-resolved peaks corresponding to the 


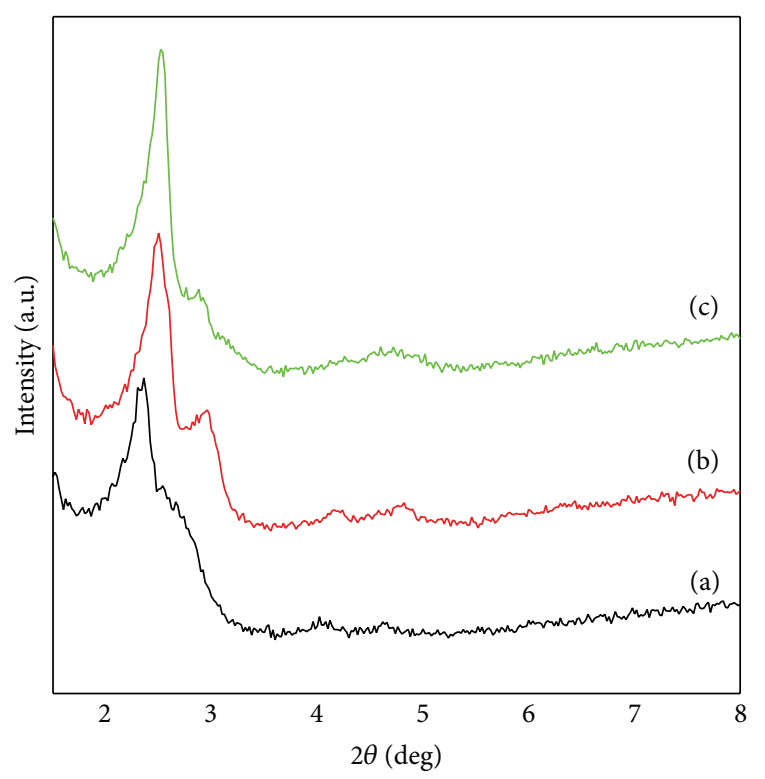

FIGURE 2: Changes in XRD patterns with drying conditions: dried in an oven at (a) $298 \mathrm{~K}$ with saturated moisture, (b) $373 \mathrm{~K}$, and (c) $298 \mathrm{~K}$ under ambient conditions.

MCM-48 structure. However, drying at a high temperature, $373 \mathrm{~K}$, seems to induce a partial structural transformation from continuous cubic MCM-48 to hexagonal MCM-41, as peaks corresponding to 110 and 200 of MCM-41 were apparent, as shown in the XRD pattern in Figure 2(b). Figure 2(c) shows that the moisture-saturated atmosphere at $298 \mathrm{~K}$ was unsuitable for formation of the MCM- 48 structure. The water vapor in the environment may prevent further condensation of silicate within the mesoporous structure.

The optimum drying time was chosen from the results shown in Figure 3. All of the samples were dried under ambient conditions. The peak intensity in the XRD pattern, which is associated with the structural order of MCM-48, increased as the drying time increased to $72 \mathrm{~h}$. When the total drying time was increased to $168 \mathrm{~h}(7 \mathrm{~d})$, however, the intensity of the XRD peak decreased slightly. Consequently, the optimum drying time was fixed at $72 \mathrm{~h}$ under ambient conditions. These experimental results indicate that filtered mesoporous silica samples must be kept in a drying oven at room temperature for at least $3 \mathrm{~d}$, without washing, to obtain reproducible synthesis of mesoporous silica at room temperature.

\subsection{Change of Mesostructure with Synthesis Mixture Compo-} sition. Based on the synthesis procedures described above, other synthesis conditions, in this case the molar ratio of $\mathrm{H}_{2} \mathrm{O}$ and $\mathrm{EtOH}$ with respect to TEOS, were investigated for the formation of mesoporous silica.

Figure 4 shows the effect of the amount of water in the solution on the formation of mesoporous silica. As the $\mathrm{H}_{2} \mathrm{O}$ : TEOS molar ratio in the reactant mixture increased from 200 to 400, the silica mesostructure changed from continuous cubic (Ia3d) MCM-48 to hexagonal MCM-41. It is

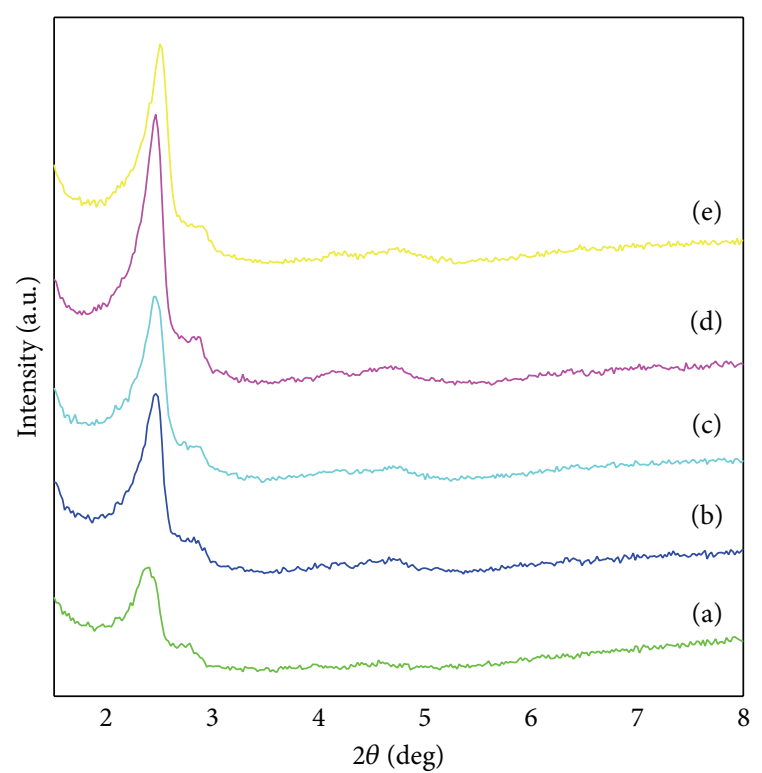

FIGURE 3: Changes in XRD patterns with drying time: (a) $30 \mathrm{~min}$, (b) $24 \mathrm{~h}$, (c) $48 \mathrm{~h}$, (d) $72 \mathrm{~h}$, and (e) $168 \mathrm{~h}$.

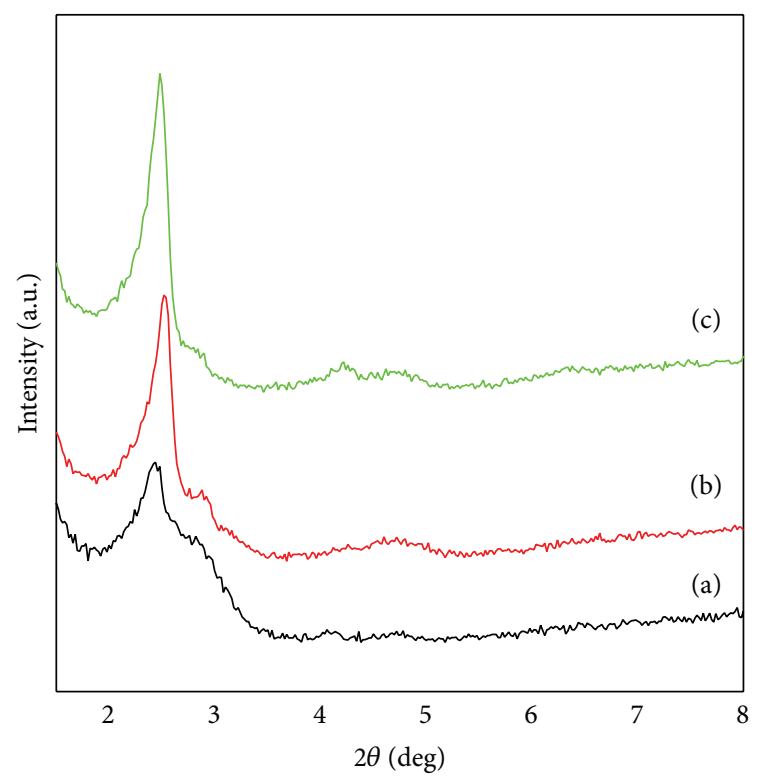

FIGURE 4: Change in XRD patterns with amount of water in the reactant mixture solution; compositions (TEOS: $\mathrm{NH}_{3}: \mathrm{EtOH}: \mathrm{CTABr}$ : $\left.\mathrm{H}_{2} \mathrm{O}=1: 20: 40: 0.2: X\right)$ are (a) $X=200$, (b) $X=300$, and (c) $X=400$.

well-known that a decrease in the surfactant micelle concentration induces a structural transformation from continuous cubic MCM-48 to hexagonal MCM-41 [5-7]. The present experimental results are consistent with previously reported results. A change in the surface curvature of surfactantsilica micelles may explain this result. The curvature of the surfactant-silicate micelles in hexagonal MCM-41 is higher than that for continuous cubic MCM-48. Thus, a decrease in the surfactant-micelle concentration under a given condition 


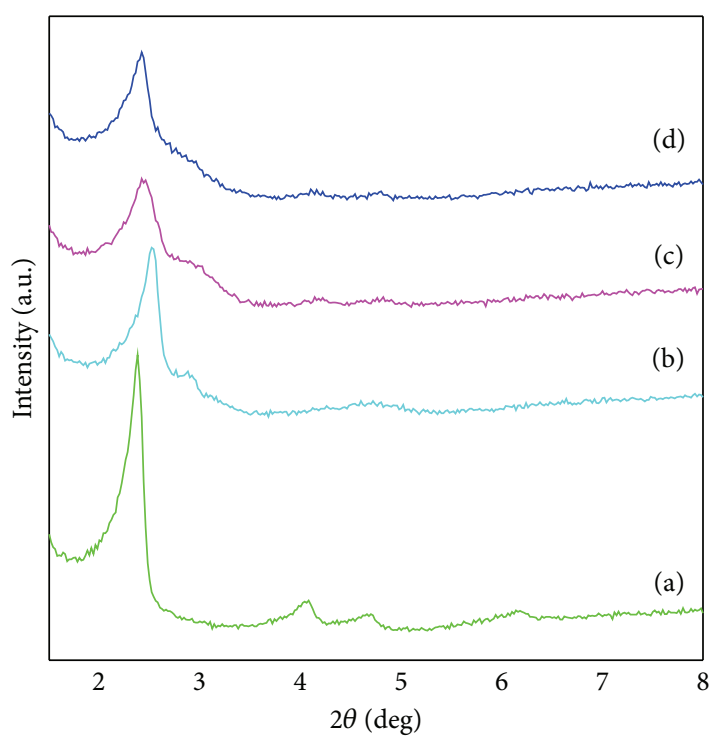

FIGURE 5: Changes in XRD patterns with amount of EtOH in the reactant mixture solution: compositions (TEOS: $\mathrm{NH}_{3}: \mathrm{EtOH}$ : CTABr: $\mathrm{H}_{2} \mathrm{O}=1: 20: X: 0.2: 300$ ) are (a) $X=20$, (b) $X=40$, (c) $X=55$, and (d) $X=70$.

increases the surface curvature, which results in a change in the mesostructure from low-curvature MCM-48 to highcurvature MCM- 41 .

Figure 5 shows the effects of the EtOH molar ratio in the reaction mixture on the formation of mesoporous silica. As the molar ratio of EtOH in the reactant mixture decreased from 40 to 20, the silica mesostructure changed from continuous cubic (Ia3d) MCM-48 to well-ordered hexagonal MCM-41. If EtOH was used as the solvent in this reaction mixture, the increase in the $\mathrm{EtOH}$ molar ratio would reduce the surfactant-micelle concentration, and a mesostructural transformation from MCM-41 to MCM-48 would normally occur. However, the experimental results showed that an increase in the EtOH molar ratio induced a transformation from MCM-48 to MCM-41. This indicates that EtOH acted not as a solvent but as a cosurfactant. Thus, EtOH appears to be incorporated inside the hydrophobic region of the micelle. The incorporated $\mathrm{EtOH}$ increases the volume of the hydrophobic portion, and this volume increase induces a decrease in the degree of micelle curvature. Bearing in mind previous results, in which addition of EtOH to the reaction mixture was a typical means of synthesizing MCM-48 in the hydrothermal synthesis method [6], the transformation of the mesostructure from MCM-41 to MCM-48 on addition of EtOH, as shown in Figure 5, further illustrates the consistency of the present result with those in previous reports.

From the XRD patterns of Figure 5, the mesopore structure of sample (a) can be assigned to MCM-41 and that of sample (b) can be assigned to MCM-48. To confirm mesopore structures, TEM images of samples corresponding to Figures 5(a) and 5(b) were obtained and displayed as shown in Figure 6. As expected in the XRD pattern, sample (a) shows well-aligned one-dimensional pores corresponding

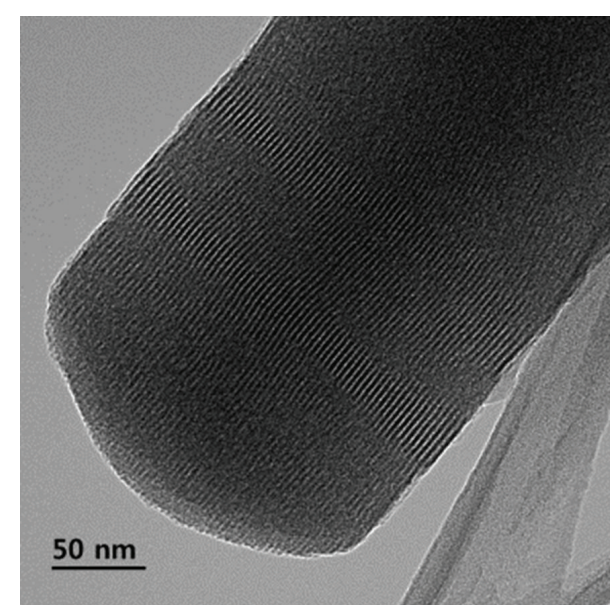

(a)

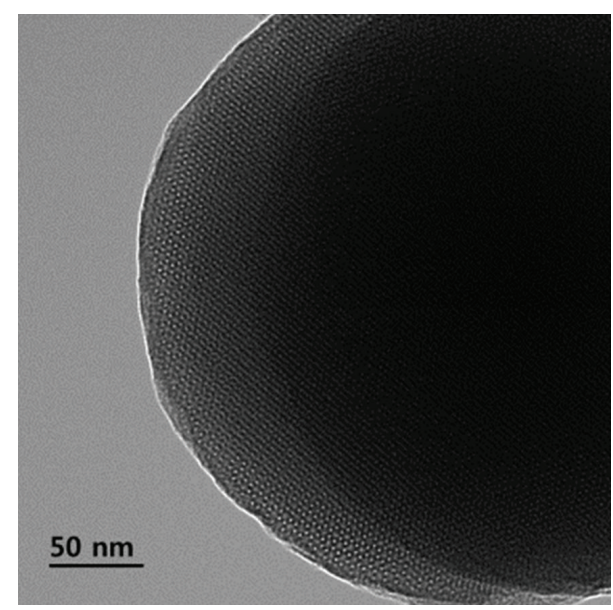

(b)

FIGURE 6: TEM images of samples obtained compositions with different molar compositions of $\mathrm{EtOH}$ in an initial reaction mixture solution: compositions (TEOS: $\mathrm{NH}_{3}:$ EtOH : CTABr : $\mathrm{H}_{2} \mathrm{O}=1: 20$ : $X: 0.2: 300$ ) are (a) $X=20$ and (b) $X=40$.

to MCM-41 structure. TEM image of sample (b) displays 3dimensional pore structure corresponding to MCM-48. It means that mesopore structures assigned by XRD patterns were confirmed by TEM images.

$\mathrm{N}_{2}$ adsorption-desorption isotherms and their pore size distributions by $\mathrm{BJH}$ method for sample (a) and sample (b) were displayed in Figure 7. Typical type IV isotherms without hysteresis and corresponding pore size distributions indicate that these samples contain mesopores and their pore size was around $3 \mathrm{~nm}$. Considering the XRD patterns, TEM images, and $\mathrm{N}_{2}$ adsorption-desorption isotherms, the mesopore structure of each sample was clearly confirmed.

In addition to the experimental conditions displayed in Figures 4 and 5, a wide range of EtOH and $\mathrm{H}_{2} \mathrm{O}$ molar ratios were investigated. These results are summarized in Figure 8. At a low molar ratio of EtOH $(\sim 20)$, the hexagonal MCM41 structure was dominant. As the EtOH ratio increased, a low-curvature mesostructured silica, MCM-48 or a layered structure (LS), was synthesized $[4,6,16]$. An increase in the 


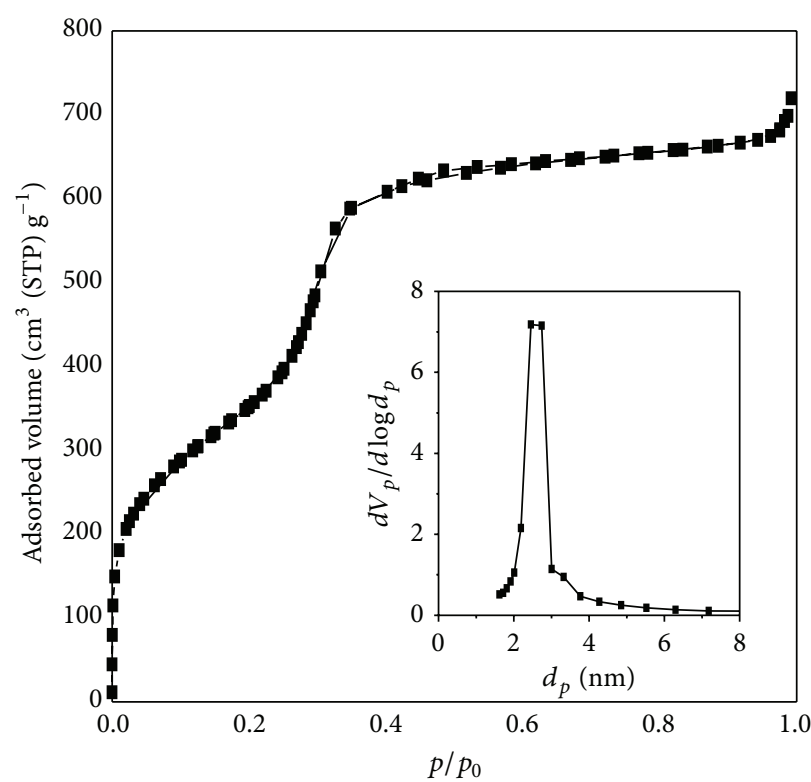

(a)

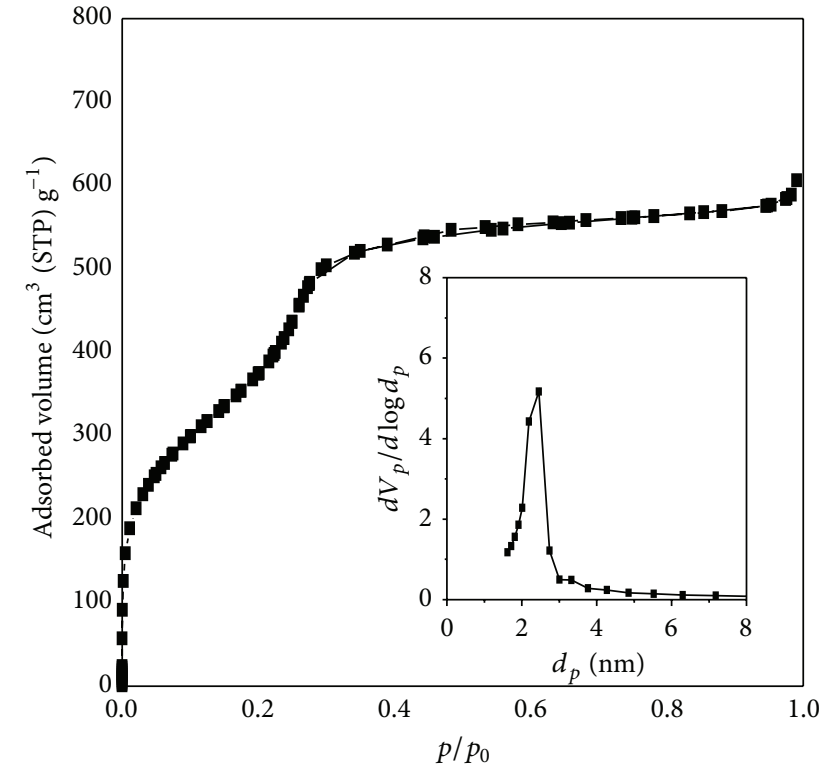

(b)

FIGURE 7: $\mathrm{N}_{2}$ adsorption-desorption isotherms and their pore size distributions of samples obtained with different molar compositions of EtOH in reaction mixture solution: compositions (TEOS : $\left.\mathrm{NH}_{3}: \mathrm{EtOH}: \mathrm{CTABr}: \mathrm{H}_{2} \mathrm{O}=1: 20: X: 0.2: 300\right)$ are (a) $X=20$ and (b) $X=40$.

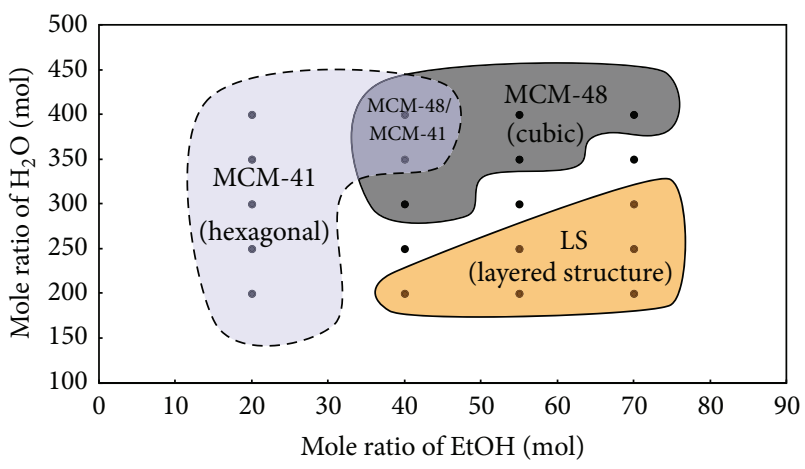

FIGURE 8: Phase diagram of mesostructures obtained with different molar compositions of EtOH and $\mathrm{H}_{2} \mathrm{O}$ in an initial reaction mixture with the following composition: TEOS : $\mathrm{NH}_{3}: \mathrm{EtOH}: \mathrm{CTABr}: \mathrm{H}_{2} \mathrm{O}$ $=1: 20: x: 0.2: y$ (the horizontal axis ( $x$-axis) represents the molar composition of EtOH and the vertical axis ( $y$-axis) displays that of $\left.\mathrm{H}_{2} \mathrm{O}\right)$.

amount of $\mathrm{H}_{2} \mathrm{O}$ and a decrease in the amount of $\mathrm{EtOH}$ tend to change MCM-48 to MCM-41 or LS to MCM-48. These types of transformation were mainly attributed to an increase in the surfactant-silica curvature. In contrast, a decrease in the amount of $\mathrm{H}_{2} \mathrm{O}$ and/or an increase in EtOH reduces the surface curvature of the silica micelle, turning MCM-41 into MCM-48 and MCM- 48 into LS.

In most cases, the as-synthesized mesoporous silica retained its structure after calcination. However, in some marginal conditions between MCM- 48 and MCM-41, indicated as a coexistence zone between MCM- 41 and MCM48, the as-synthesized MCM- 48 became MCM- 41 after calcination, as shown in Figure 9. This indicates that further

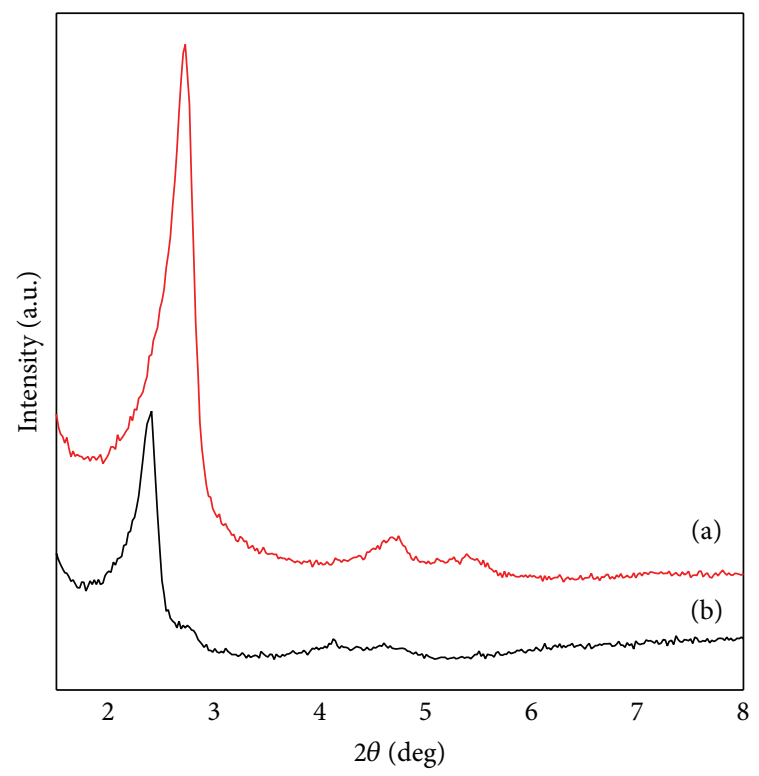

FIGURE 9: Changes in mesostructure before and after calcinations for a reaction mixture composition of TEOS : $\mathrm{NH}_{3}: \mathrm{EtOH}: \mathrm{CTABr}$ : $\mathrm{H}_{2} \mathrm{O}=1: 20: 40: 0.2: 400$; (a) after calcination and (b) assynthesized.

silicate condensation occurred; the increased curvature of the mesostructured silica probably produced MCM- 41 instead of MCM-48. This result may be one of the evidences supporting the cooperative mechanism $[4,5]$.

Figure 10 shows the effects of the $\mathrm{NH}_{3}$ molar ratio on formation of the silica mesostructure. As the molar ratio of $\mathrm{NH}_{3}$ in the reaction mixture increased from 10 to 30 , the 


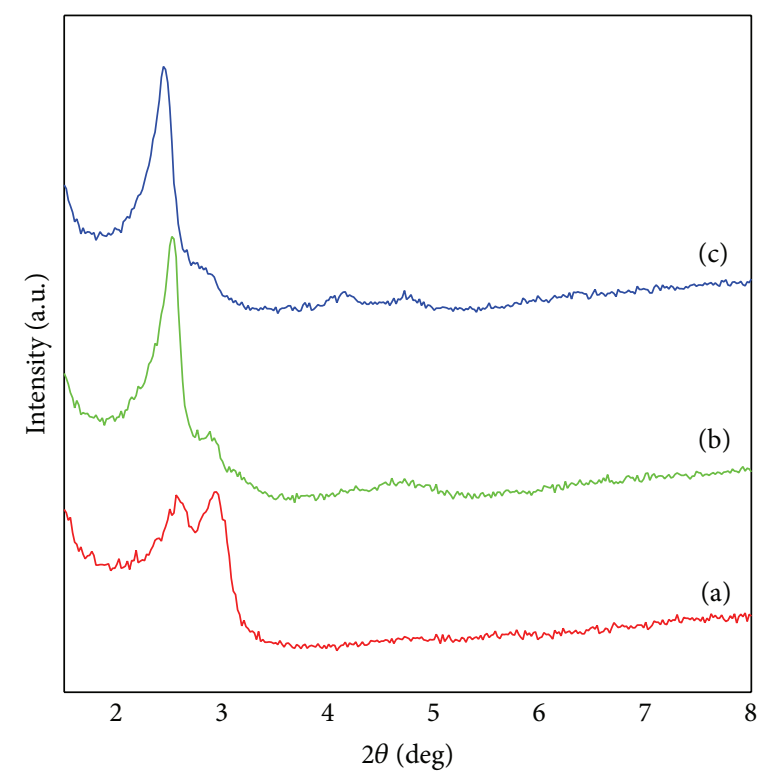

FIGURE 10: Effects of $\mathrm{NH}_{3}$ molar ratio on formation of silica mesostructure: the molar composition of the reaction mixture was fixed as follows: TEOS : $\mathrm{NH}_{3}: \mathrm{EtOH}: \mathrm{CTABr}: \mathrm{H}_{2} \mathrm{O}=1: x: 40: 0.2: 400$; the $\mathrm{NH}_{3}$ molar ratio was (a) $x=10$, (b) $x=20$, and (c) $x=30$.

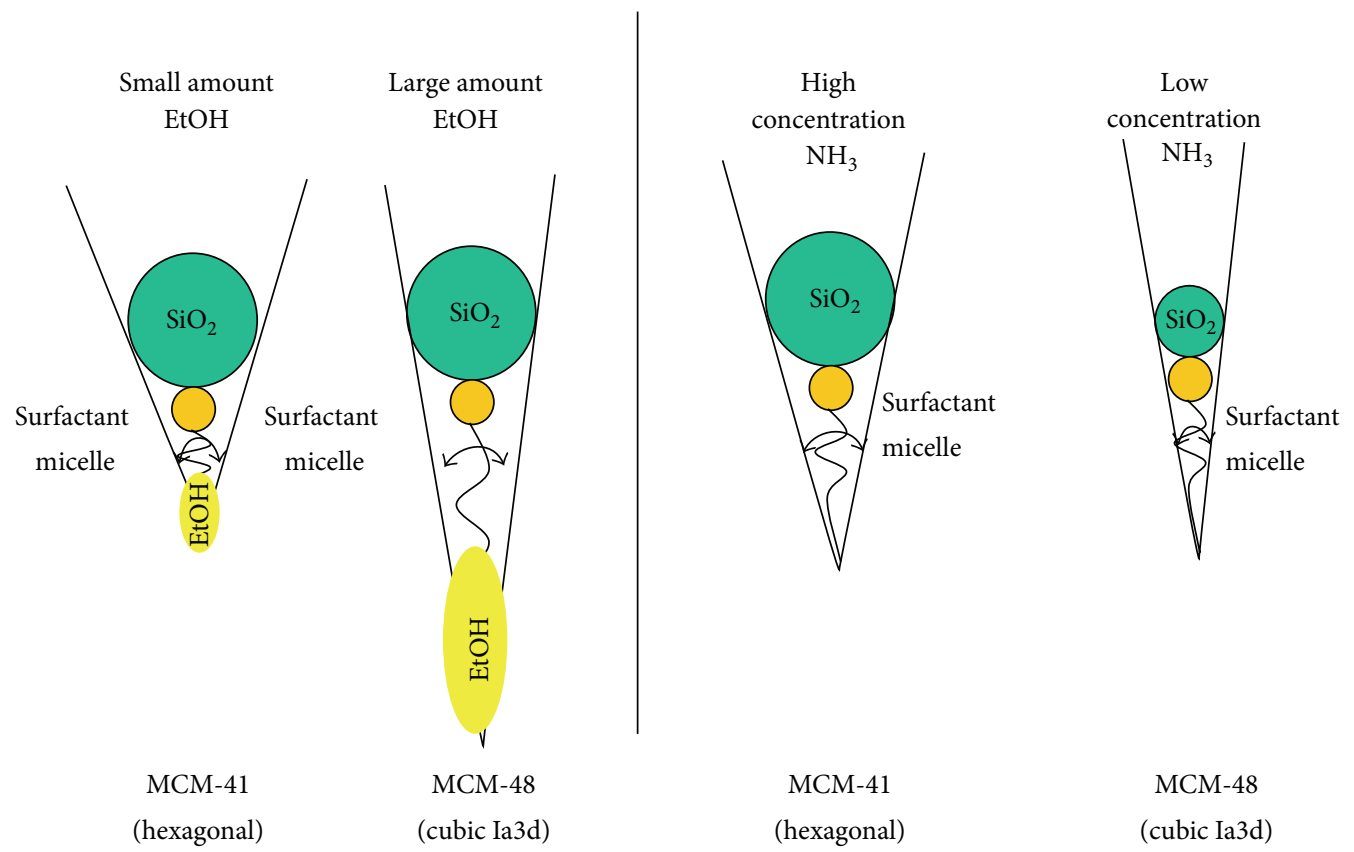

SCHEME 1: The surface curvature change of the silica-surfactant micelle assembly depending on the EtOH amount and the silica particle size, controlled by $\mathrm{NH}_{3}$ concentration.

silica mesostructure changed from undefined silica to MCM48 and finally to MCM-41. Although Figure 10(a) shows an undefined mesostructure, Figure 10(b) displays a distinct transformation from MCM-48 to MCM-41. As is the case with $\mathrm{H}_{2} \mathrm{O}$, the increase in the $\mathrm{NH}_{3}$ molar ratio increases the curvature of the surfactant-silica micelle. The role of $\mathrm{NH}_{3}$, however, appears to differ from that of $\mathrm{H}_{2} \mathrm{O} . \mathrm{NH}_{3}$ was used as a silicate condensation agent, and its concentration is closely related to the particle size of the silica incorporated in the micelle. A high concentration of $\mathrm{NH}_{3}$ may increase the silica particle size. Thus, the surface curvature of the micelle increased and eventually caused transformation of MCM-48 to MCM-41.

All the present experimental results can be interpreted by the proposed surfactant-silica micelle model shown in Scheme 1. As EtOH was a cosurfactant, an increase in the EtOH molar ratio resulted in a decrease in the micelle curvature. The decrease in the silica particle size due to the 
low $\mathrm{NH}_{3}$ concentration also reduced the degree of micelle curvature. Thus, the surface curvature of the silica-surfactant micelle in this case transformed the silica mesopore structure from MCM-41 to MCM-48.

\section{Conclusion}

Mesoporous silica materials were synthesized at room temperature using TEOS as the silica source, CTABr as a surfactant, ethanol as a cosurfactant, and ammonia as an agent for silicate condensation. The pore structure of the mesoporous material was controlled by changing the reaction mixture composition. Unlike the case in conventional hightemperature synthesis of mesoporous silica, the drying process after filtration requires special care to assure reproducible experimental results.

\section{Conflict of Interests}

The authors declare that there is no conflict of interests regarding the publication of this paper.

\section{Acknowledgments}

This work was supported by the New \& Renewable Energy Core Technology Program of the Korea Institute of Energy Technology Evaluation and Planning (KETEP), granted financial resource from the Ministry of Trade, Industry and Energy, Republic of Korea (20123010040010). This research was also supported by Basic Science Research Program through the National Research Foundation of Korea (NRF) funded by the Ministry of Education (2012R1A1A4A01019828).

\section{References}

[1] C. T. Kresge, M. E. Leonowicz, W. J. Roth, J. C. Vartuli, and J. S. Beck, "Ordered mesoporous molecular sieves synthesized by a liquid-crystal template mechanism," Nature, vol. 359, no. 6397, pp. 710-712, 1992.

[2] J. S. Beck, J. C. Vartuli, W. J. Roth et al., "A new family of mesoporous molecular sieves prepared with liquid crystal templates," Journal of the American Chemical Society, vol. 114, no. 27, pp. 10834-10843, 1992.

[3] N. Pal and A. Bhaumik, "Soft templating strategies for the synthesis of mesoporous materials: inorganic, organic-inorganic hybrid and purely organic solids," Advances in Colloid and Interface Science, vol. 189-190, pp. 21-41, 2013.

[4] A. Monnier, F. Schüth, Q. Huo et al., "Cooperative formation of inorganic-organic interfaces in the synthesis of silicate mesostructures," Science, vol. 261, no. 5126, pp. 1299-1303, 1993.

[5] A. Firouzi, D. Kumar, L. M. Bull et al., "Cooperative organization of inorganic-surfactant and biomimetic assemblies," Science, vol. 267, no. 5201, pp. 1138-1143, 1995.

[6] J. M. Kim and R. Ryoo, "Synthesis of MCM-48 single crystals," Chemical Communications, no. 2, pp. 259-260, 1998.

[7] R. Ryoo, S. H. Joo, and J. M. Kim, "Energetically favored formation of MCM-48 from cationic-neutral surfactant mixtures," Journal of Physical Chemistry B, vol. 103, no. 35, pp. 7435-7440, 1999.
[8] M. Ogura, H. Miyoshi, S. P. Naik, and T. Okubo, "Investigation on the drying induced phase transformation of mesoporous silica; A comprehensive understanding toward mesophase determination," Journal of the American Chemical Society, vol. 126, no. 35, pp. 10937-10944, 2004.

[9] S. Che, S. Kamiya, O. Terasaki, and T. Tatsumi, "The formation of cubic $P m 3 \bar{n}$ mesostructure by an epitaxial phase transformation from hexagonal p6mm mesophase," Journal of the American Chemical Society, vol. 123, no. 48, pp. 12089-12090, 2001.

[10] M.-C. Liu, H.-S. Sheu, and S. Cheng, "Drying induced phase transformation of mesoporous silica," Chemical Communications, no. 23, pp. 2854-2855, 2002.

[11] D. Grosso, F. Babonneau, G. J. D. A. A. Soler-Illia, P.-A. Albouy, and $\mathrm{H}$. Amenitsch, "Phase transformation during cubic mesostructured silica film formation," Chemical Communications, no. 7, pp. 748-749, 2002.

[12] F. Cagnol, D. Grosso, G. J. D. A. A. Soler-Illia et al., "Humiditycontrolled mesostructuration in CTAB-templated silica thin film processing. The existence of a modulable steady state," Journal of Materials Chemistry, vol. 13, no. 1, pp. 61-66, 2003.

[13] R. Ryoo, C. H. Ko, S. J. Cho, and J. M. Kim, "Optically transparent, single-crystal-like oriented mesoporous silica films and plates," Journal of Physical Chemistry B, vol. 101, no. 50, pp. 10610-10613, 1997.

[14] K. Schumacher, M. Grün, and K. K. Unger, "Novel synthesis of spherical MCM-48," Microporous and Mesoporous Materials, vol. 27, no. 2-3, pp. 201-206, 1999.

[15] M. Grün, K. K. Unger, A. Matsumoto, and K. Tsutsumi, "Novel pathways for the preparation of mesoporous MCM-41 materials: control of porosity and morphology," Microporous and Mesoporous Materials, vol. 27, no. 2-3, pp. 207-216, 1999.

[16] O. I. Lebedev, G. van Tendeloo, O. Collart, P. Cool, and E. F. Vansant, "Structure and microstructure of nanoscale mesoporous silica spheres," Solid State Sciences, vol. 6, no. 5, pp. 489498, 2004.

[17] W. Stöber, A. Fink, and E. Bohn, "Controlled growth of monodisperse silica spheres in the micron size range," Journal of Colloid And Interface Science, vol. 26, no. 1, pp. 62-69, 1968. 

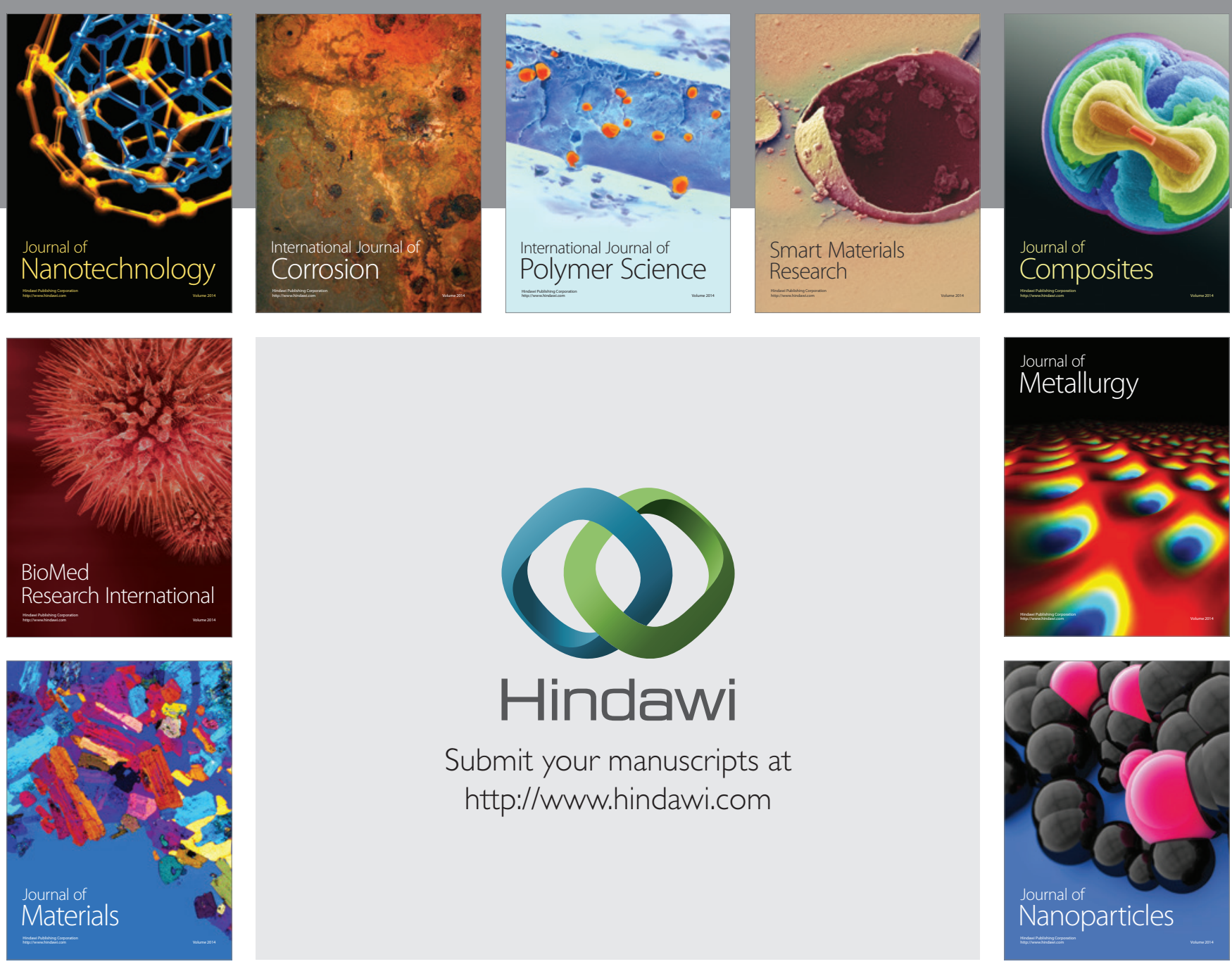

Submit your manuscripts at http://www.hindawi.com
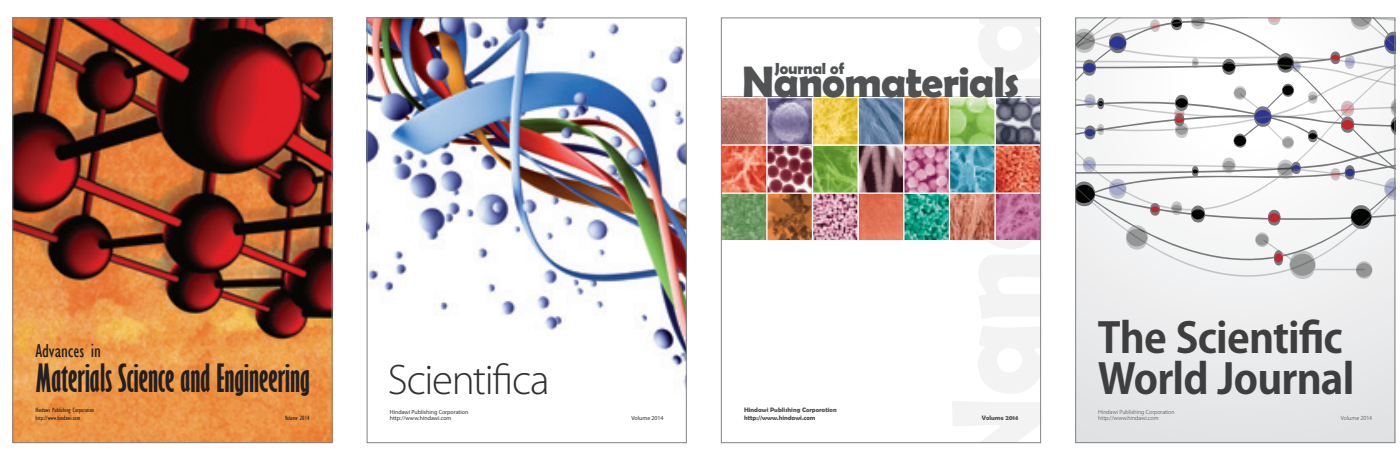

\section{The Scientific World Journal}
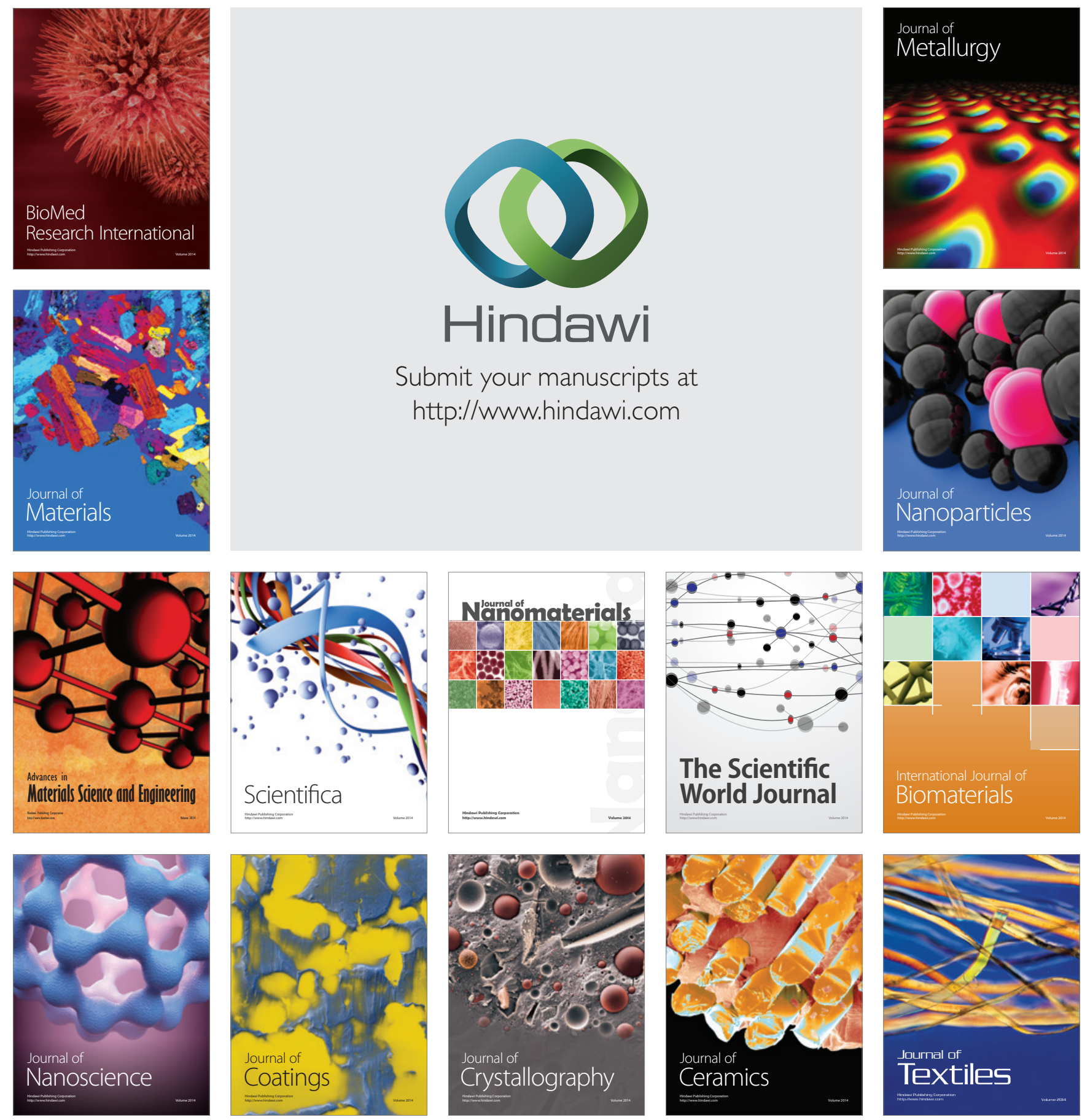